Boise State University

ScholarWorks

$1-20-2016$

Albertsons Library Data Management Strategic Agenda

\author{
Margie Ruppel \\ Boise State University \\ Megan Davis \\ Boise State University \\ Michelle Armstrong \\ Boise State University \\ Amber Sherman \\ Boise State University
}

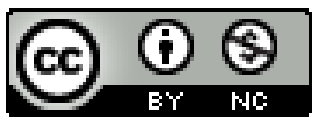

This work is licensed under a Creative Commons Attribution-Noncommercial 4.0 License 


\title{
Albertsons Library Data Management Strategic Agenda
}

\author{
Revised January 20, 2016
}

The following Strategic Agenda outlines areas of emphasis and specific activities that Albertsons Library will engage in over the next two years (January 2015 - December 2016) in support of its data management services initiative. These activities will help define an evolving framework where the library serves as an active partner throughout the scholarly and research lifecycle. The foundation for this framework is a commitment to collaboration, open information sharing and discovery, and a focus on providing point of need services.

\section{BACKGROUND STATEMENT}

Boise State University identifies research and creative activity as a Core Theme of its institutional mission. This concept is clarified through several objectives which outline the importance of transferring knowledge for "societal, economic, and cultural benefits". The university expects its work to have "substantial disciplinary impact and contributes to the overall reputation of the university," so that, "community members can connect with and benefit from our researchers, artists, and students." This core theme of scholarly contribution is further confirmed in the university's Goals and Strategies which detail specific activities Boise State will undertake. For example in goals 3 and 5, Boise State establishes its commitment to effective research and creative efforts by investing in developing key competencies, building necessary infrastructures, and encouraging external funding and philanthropic support.

In consideration of these university goals, Albertsons Library is also actively advocating for Boise State's research and creative activities through its own Strategic Plan. In Library Strategic Objective 4, Albertsons Library has committed to identifying "critical areas of needed Research Support then build expertise, capacity and services to meet these needs." In pursuit of this objective, library personnel will "collaborate with other campus units to build the expertise and resources needed to support the discovery, management, and use of data sets."

To achieve this objective, library personnel have already engaged in a variety of activities to ensure the proactive management of Boise State's data sets. To date, the Albertsons Library has:

- Hosted a series of training sessions to increase all library personnel's awareness and value of data sets as a key university asset.

- Co-hosted university-wide data management workshops with the Office of Sponsored Programs (OSP) and Office of Information Technology (OIT).

- Completed initial customizations to the DMPTool, an online resource allowing researchers to create data management plans specific to institutional and funder requirements.

- Created an online site providing easy access to data management resources and tools.

- Conducted data interviews with faculty across the campus. 
- Begun providing data management consultation and reference services.

- Established a Core Data Management Team (Core Team) ${ }^{1}$ responsible for identifying and facilitating the library's on-going data management initiatives.

The following Strategic Agenda outlines activities Albertsons Library will engage in over the next two years, Phase I.

PHASE I (January 2015 - December 2016)

\section{Increase data management skill sets across campus through instructional efforts.}

- Activity 1.1: Continue to develop current data management information resources in response to campus researchers and library staff needs.

Maintain a comprehensive website with information and support tools so that Boise State University researchers can develop effective data management plans. Maintain an internal Google site to collect data management-related information including readings, continuing education and instruction resources, and relevant tools for the Core Team.

Lead: Core Data Management Team

Partners: None

Timeline: On-going

Update Status - In Process: The Core Team currently maintains a library guide of useful data management resources and is working to transition the content to a separate "Researcher Support" web site. A separate, internal Google site is maintained to assist with planning and working documents.

$\circ$ Activity 1.2: Strategically educate researchers about data management and data management planning.

Combine general campus-wide education with targeted department-level workshops about data management. Offer general, campus-wide data management workshops. Work with individual colleges, schools, and departments to provide discipline-focused data management workshops. Incorporate data management information as part of the library orientation session for new faculty prior to the start of each fall semester.

Promote data management resources including the data management library guide and DMPTool to university researchers.

\footnotetext{
${ }^{1}$ The Core Data Management Team is comprised of Michelle Armstrong, Megan Davis, Margie Ruppel, and Amber Sherman. 
Lead: Core Data Management Team

Partners: OSP, library faculty liaisons, college and department-level grant coordinators Timeline: On-going

Update Status - In Process: Basic data management resources were presented to new faculty during the August New Faculty Orientation. The Core Team is also exploring hosting a series of research support workshops in collaboration with the Division of Research and Economic Development.

- Activity 1.3: Educate graduate students by creating instructional content for research courses.

Develop data management instructional modules to be incorporated into relevant undergraduate and graduate research courses. Utilize relevant faculty input to develop the modules and implement it in the most effective way.

Lead: Megan Davis

Partners: Core Data Management Team and campus faculty members

Timeline: Have instructional modules available for faculty by Fall 2016 (pilot test during Summer 2016).

Update Status - In Process: A data management curriculum survey has been developed and received IRB approval. It will be issued to faculty teaching research methods courses in February 2016. Responses to the survey will serve as the foundation for the instructional content.

- Activity 1.4: Increase data management competencies across library staff.

Continue to offer a variety of training opportunities for entire library staff, including shorter "Data Dish" sessions and more in-depth sessions as topics/resources warrant.

Lead: Core Data Management Team

Partners: None

Timeline: On-going, with estimate of 3 sessions per academic semester

Update Status - In Process: The Core Team has hosted 3 Data Dishes and a webinar on finding data sets. Additional training sessions have been scheduled for Spring 2016. 


\section{Provide an infrastructure (tools, policies, direct services, staffing, etc.) to actively manage Boise State's research to make it discoverable and accessible.}

- Activity 2.1: Help identify and track Boise State's data sets by working with the Office of Sponsored Programs and Office of Information Technology.

There have been several efforts to identify Boise State data sets. These activities have included listing data related to a specific grant project, creating administrative metadata associated for data housed on the OIT servers, and development of the Boise State Data Portal. Similarly, several faculty noted as part of the data interview project that they would like others to know about the data assets they manage, as well as be able to find similar Boise State data sets. The Core Team will work with its various partners to help identify, locate, and determine management responsibilities for these assets. These activities may involve the creation of a tracking system or further development of existing data discovery tools.

Lead: Amber Sherman

Partners: OIT, OSP, College-level grant writing staff, ORC, individual researchers Timeline: September 2015 - December 2016 (Data sets for at least 3 departments will be tracked by the end of Phase I.

Update Status - In Process: A data sets collection is being set up in ScholarWorks and can be used to hold descriptive metadata records for any Boise State data set. Members of the Core Team are exploring how this information can be used to identify and track Boise State's data assets.

- Activity 2.2: Develop a data management plan template in collaboration with OIT to help manage and facilitate data discovery.

Create a customized, institution-level data management plan template using the DMPTool specifically for data sets stored on OIT servers. Metadata is one crucial component the template needs to facilitate data discovery. Before creating this template, the Library will talk to OIT to discover their needs, and look at other university storage processes and policies. In addition, other campus stakeholders and their specific requirements will need to be identified, and that information incorporated into the template.

Lead: Margie Ruppel

Partners: OIT (possibly Office of Technology Transfer, Office of Research Compliance, and individual grantors)

Timeline: First draft by May 2015 
Update Status - Completed: A basic DMP template has been created to help OIT manage data stored on their servers. Further revisions will be made once staff from OIT respond to requests for feedback.

- Activity 2.3: Conduct a demonstration project utilizing a local researcher's data to identify the potential scope of library metadata services.

In collaboration with a Boise State researcher, the demonstration project will be designed to determine the feasibility, distinct processes, various objectives, and participant roles needed to deliver library metadata services. Based on this project, the Core Team will report to the Library administration recommendations for next steps in this area.

Lead: Amber Sherman

Partners: Individual researcher to be identified

Timeline: Fall 2015

Update Status - Completed: Amber Sherman worked with members of the MILES grant project to explore supporting researcher's metadata needs. A summary of the time required and tasks completed was submitted to the Core Team. This information was then used to develop a metadata librarian job description.

- Activity 2.4: Explore integrating Boise State data into NKN, DataOne, Dryad, and ICPSR.

One of the most important ways of increasing the visibility of the work of Boise State researchers is to make data sets available through publicly accessible data repositories. Albertsons Library already provides several resources for researchers to explore smaller discipline-specific repositories, but there are several larger repositories that the Core Team would like to investigate in more detail. The Core Team will review the policies and procedures for the Northwest Knowledge Network (NKN), DataOne, Dryad, and the Inter-university Consortium for Political and Social Research (ICPSR). Based on the findings of these investigations, the Core Team will identify possible partnerships the university could establish with these repositories, possible support services the library could provide, and any administrative/funding support needed to utilize these repositories.

Lead: Core Team

Partners: None

Timeline: Ongoing 
Update Status - In Process: By working with MILES staff, the Core Team has become familiar with the NKN system and the features it provides.

\section{Facilitate researcher data management activities by providing point of need services.}

- Activity 3.1 Consult with individual Boise State University researchers on their data management plans and related needs.

Provide time-sensitive, personalized data management consultations with Boise State University researchers at their point of need. Recognizing that researchers have a broad range of requirements related to creating data management plans, librarians will utilize data interviews to assess researcher needs. During the data interview, the librarian can determine the level of support needed and begin to implement the appropriate services.

Lead: Core Data Management Team

Partners: Boise State reference librarians and library faculty liaisons Timeline: On-going

Update Status - In Process: After meeting with researchers across campus, the Core Team released a data management needs report. They are also exploring ways they can proactively reach out to researchers who are creating data management plans.

- Activity 3.2 Educate Boise State University faculty in the best ways to publish their data sets as scholarship.

Provide Boise State University researchers with the information they need to publish data sets in scholarly, tenure-worthy venues such as data journals. Creating and publishing data sets can help a researcher earn recognition in their field for having the skills to perform experiments and observations; increase their visibility when other researchers use their data; gain credit towards promotion and tenure; and promote open science and open access. Educate researchers on these opportunities through workshops, department flyers, email messages, and a checklist.

Lead: Margie Ruppel and Amber Sherman

Partners: Boise State department faculty representatives

Timeline: September 2015 - December 2016 
Update Status - In Process: After reviewing data publishing options, a workshop presentation is being developed and is expected to be offered to the campus in Fall 2016.

- Activity 3.3: Create targeted support tools (checklists, helpful tips, FAQs, etc.) for faculty, graduate students, and other campus researchers.

In response to Boise State researchers needs, appropriate data management tools will be integrated into the processes of partner campus units. The Core Team envisions these support tools to be helpful and time-saving and may include checklists, tip sheets, instructions, and FAQs created in response to the needs of campus researchers. A parallel goal (\#5) is to "Increase and strengthen relationships and active collaborations with both institutional and regional partners."

Lead: Core Data Management Team

Partners: OSP, ORC, and other units as identified

Timeline: June 2015 - December 2016

Update Status - In Process: The Core Team has met with members of the ORC staff and OIT Information Security Officer to discuss ways that data management planning can be managed in a way to ensure best practices.

○ Activity 3.4 Continue to customize and maintain the DMPTool.

The Core Team will lead an effort to customize and maintain the DMPTool, which facilitates the creation of data management plans using templates based on large grant funders. Each organization requires specific elements in the data management plans that are a part of grants submitted to them. While Boise State University has customized the templates currently in the DMPTool, there is a need to update the language used in current templates.

Lead: Core Team

Partners: OIT staff and college and department-level grant coordinators

Timeline: June 2015 - December 2016

Update Status - In Process: Members of the ScholarWorks staff are exploring creating a ScholarWorks specific data management planning template to support faculty submitting their materials to the ScholarWorks Data Set Collection. 


\section{Increase library personnel resources focused on data management services.}

- Activity 4.1: Facilitate the formal and ad hoc assignments of data management job duties in response to developing services and projects.

As with all areas of library services, data management services are being designed to proactively identify ways that the library can be a collaborative research partner, as well as provide "point of need" resources. As a result, this approach relies on an evolving and flexible staffing model. To efficiently facilitate a responsive workforce, the Core Team will communicate with the library's administration, including individual unit heads, any ad hoc and on-going staffing needs. These conversations will include discussions regarding allocation of staff time, needed skills sets, timeframe, and strategies for reducing burdens on current staff and projects.

Where appropriate, the Core Team will work with other university departments to identify shared staff positions and assist in advocating at a university-level the need for and funding of skilled data managers.

Lead: Michelle Armstrong

Partners: OSP, OIT, Individual research groups

Timeline: On-going

Update Status - In Process: The Core Team has explored a variety of ways of effectively directing personnel resources to data management needs. Megan Davis and Margie Ruppel continue to have a portion of their assigned workload allocated to data management. The Library is developing a campus-wide data management proposal which includes support for a metadata librarian and data manager. The Library has worked with the MILES project to allocate office space for for their part-time data manager.

○ Activity 4.2: Develop metadata skills in-house

Efforts will be undertaken to increase in-house skills and service capacity in the area of metadata creation. This includes self-education activities, participation in formal learning opportunities, and hosting library-wide events. Library staff will be encouraged to self-identify their interest in this area which will allow the Core Team to facilitate support for release time, training funds, and evaluation recognition for their participation and skill development. By increasing capacity throughout the library's personnel, Albertsons Library will be able to more quickly respond to specific research projects, and operationalize and sustain needed metadata services. Activity 4.3 details the strategies that will be used to acquire dedicated metadata librarian services. 
Lead: Core Data Management Team

Partners: None

Timeline: September 2015 - December 2016

Update Status - In Process: Through the metadata project and creation of the ScholarWorks Data Set Collection, Library staff are developing competencies with Dublin Core Metadata and ISO 19115 schema. As new projects are developed, additional competencies are expected to be developed.

○ Activity 4.3: Acquire a metadata librarian.

Academic libraries have an established presence in the data management arena. Common metadata services include creation of templates and specific metadata sets, compliance with individual metadata schema, and assistance with submission to appropriate repositories. The complexity of these activities can vary greatly depending on the specific project. The common elements for all of these tasks however, are quality management and discovery of data assets. Currently, Albertsons Library does not have a trained librarian on staff to provide this broad metadata expertise and leadership. Hiring a metadata librarian and acquiring the on-going financial support will be a priority during Phase I. To pursue this goal, the Core Team will:

- Create a complete job description, including expected salary, for a metadata librarian that can be shared with all campus stakeholders.

- Use multiple communication methods to advocate to library and university administration the need for the position (data interview report, annual budget request, metadata demonstration project results).

- Explore alternate service delivery models, including outsourcing and consortia with regional universities.

Lead: Core Data Management Team

Partners: Library and University Administration

Timeline: Ongoing

Update Status - In Process: A metadata librarian position has been incorporated into the campus-wide data management proposal. NKN services have also been reviewed as an alternative to in-house metadata staff.

- Activity 4.4: Continue to develop the Core Team's competencies and skills

The Core Team already has a successful record of self-development. These efforts have provided them the ability to advocate and provide leadership for the library's data 
management initiatives. To continue this progress, the Core Team will actively pursue formal learning opportunities, as well as engage in self-education activities.

Lead: Core Data Management team

Partners: None

Timeline: On-going

Status Update - In Process: Michelle Armstrong attended a Data Carpentry workshop in Summer 2015. Additional resources, information, and experiences are shared during weekly Core Team meetings.

\section{Increase and strengthen relationships and active collaborations with both institutional and regional partners.}

- Activity 5.1: Seek partnerships by exploring the integration of library data management services into university processes.

As noted previously, library data management services should be designed to provide point of need support for researchers. However, much of the data management activities involve systems, such as the grant proposal process, that the library is not currently engaged with. To deliver this ideal of "point of need", the Core Team will seek out partners and services that would benefit from library support. This review will include looking at related university policies and requesting guidance from OSP personnel regarding projects or systems that would be receptive to such collaborations. Once identified, the Core Team will use a project management approach to identify and prioritize appropriate points of integration and work with these partners to develop methods of providing library support services via their systems.

Lead: Core Data Management Team

Partners: OSP, Graduate College, OIT, School of Public Service

Timeline: July 2015 - December 2016

Update Status - In Process: Members of the Core Team actively participate in a variety of meeting and collaborative projects. The Library is also helping host the Coffee \& Donuts with Researchers events.

- Activity 5.2: Identify possible partnerships with other data management professionals, especially those located in the Northwest region.

With limitations on available financial resources and dedicated personnel, the library will explore external collaborations to deliver needed data management services. The 
focus of these discussions will be with library and data management personnel at the University of Idaho, as well as other data management professionals in the Northwest region.

Lead: Core Data Management Team

Partners: TBD

Timeline: January - December 2016

Update Status - In Process: By participating in the Data Carpentry Workshop, a member of the Core Team was able to meet other data managers in the Northwest region. Boise State librarians arranged a dinner with University Idaho librarians during the Idaho Library Association conference. Amber Sherman has participated in a variety of meetings with the MILES and NKN staff.

\section{Gather needed information to inform Phase II.}

- Activity 6.1: Conduct an environmental scan of campus data management needs and activities in order to make decisions about future services and priorities.

To prepare for Phase II and to best meet the needs of the Boise State research community, an environmental scan will be administered with consideration given to all relevant campus partners. This will likely consist of interviews and surveys to identify strengths and gaps in the university's current data management services and resources. Results of the scan will provide direction for Phase II of the Core Team's strategic agenda.

Lead: Core Data Management Team

Partners: OSP and OIT

Timeline: July - December 2016

Update Status - Pending

\section{ORGANIZATIONAL IMPLICATIONS}

- Budget: When developing this strategic agenda, special consideration has been given to possible impact on the library's budget. Understanding the spending restrictions and funding reductions recently enacted by the university, activities were selected with several criteria in mind. First, activities were selected that focused on advocating for increased support for data management services campus-wide. As a new area of focus, it is important to help university administration understand the benefits, which include increased research recognition and funding, that active management of Boise State's data assets can provide. Second, activities must be able to be 
accomplished with current library staffing and financial resources. Although the strategies are designed to be aspirational, there are limitations to commitments that can be made with our partners in the delivery of services based on budgetary and personnel restrictions. With this understanding, the Core Team will actively explore alternative funding and staffing options.

At this time the Core Team has not identified additional technology or cyberinfrastructure needs. If such university-wide needs arise, the group will work with OIT and OSP to provide these resources. If the tools or resources are specifically for library personnel use, the Core Team will work with the library administration as described above.

- Personnel: Varying impacts are expected on the library personnel and therefore changes in this area will involve on-going conversations with the library's administration, as well as individual unit heads. The goals of these conversations will be to ensure adjustments occur in such a way as to reduce impact on individuals and units, and instead complement and enhance the library's existing services and resources. Additionally, a special focus will be made to provide recognition of personnel participating in data management services. This may include position description updates, certification of learning, or other acknowledgement of personnel contributions.

- Core Data Management Team: Members of this group are responsible for identifying and facilitating the library's on-going data management initiatives. To fulfill this objective, they will work with their direct supervisors to ensure the appropriate adjustments of time and duties are made.

- All Library Personnel: Data management has become a standard part of academic and research library services. All library employees are expected to develop a general understanding of the value and importance of data management services and have a familiarity with common data management resources. In support of this expectation, it is the responsibility of the Core Team, with approval from the library's administration, to provide on-going learning opportunities for all library personnel.

- Library Liaisons: As primary contacts for academic departments, library liaisons should be able to facilitate a data management interview as a method of discovering individual researcher needs. Although these activities will not require additional time, liaisons will need to be prepared to serve as the first point of contact for their departments.

- Outreach: Data management services provided by the library are available to any faculty, student, or affiliated researcher. However, to ensure that these services are available to researchers at their specific point of need, the library, in collaboration with its institutional partners, will target individual groups or departments for training and support. The team will also use the library's existing outreach and promotion services to continue to raise the awareness and value of data management on campus.

- Institutional Partners: Partnership is a key tenet of any data management service involving the library. With this in mind, the Core Team will collaborate with key institutional partners to 
develop and deliver these services. The expectation is that many of the data management services will be co-delivered with these partners. Current collaborators include the Office of Sponsored Programs and the Office of Information Technology. Other potential partners could include other units in the Division of Research and Economic Development, the Graduate College, and college and department-level grant coordinators.

- External Partners: Explorations with external partners may have the potential to reveal a variety of opportunities for the Library and University at large. As the conversations progress, the Core Team will share information with Library Administration and the Library Leadership Team to help identify the specific implications.

\section{PHASE II (January 2017 - TBD)}

With the completion of Phase I, it is expected that the library will be viewed as a valued research partner across campus. This change will expand the library's current role of one of supporting researchers primarily during the literature review stage, to one of engaging with them throughout the scholarly communication lifecycle. This evolved position will also demonstrate the increased personnel readiness within the library resulting from intentional skill development, internal capacity building, and active engagement in data projects.

It is also expected that as a result of the activities carried out in Phase I, the library will have connected with campus-wide partners who will be able to serve as advocates for the on-going development of library data management services. These partners will not only value these services, but will also assist in the further development and delivery of them.

Having reached this level of integration and collaboration, Phase II will focus on expanding services, particularly in the area of individual project data management support and increased data description and discovery. Activities will be chosen based on the information provided by the Fall 2016 environmental scan (see Activity 6.1.)

This agenda is based on the Oregon State University Libraries and Press Strategic Agenda for Research Data Services.

Created - January 2015

Updated - January 20, 2016 